\title{
Critical Incident Reported in an Obstetric Unit of a Tertiary Care Hospital of a Developing Country, over a Period of Two Years
}

\author{
Shemila Abbasi \\ Department of Anaesthesiology, Aga Khan University, Karachi, Pakistan \\ Email: shemila.abbasi@aku.edu
}

How to cite this paper: Abbasi, S. (2017) Critical Incident Reported in an Obstetric Unit of a Tertiary Care Hospital of a Developing Country, over a Period of Two Years. Open Journal of Obstetrics and Gynecology, 7, 1228-1238.

https://doi.org/10.4236/ojog.2017.712125

Received: October 24, 2017

Accepted: November 27, 2017

Published: November 30, 2017

Copyright $\odot 2017$ by author and Scientific Research Publishing Inc. This work is licensed under the Creative Commons Attribution International License (CC BY 4.0).

http://creativecommons.org/licenses/by/4.0/

\begin{abstract}
Introduction: A lot of literature is available on critical incidents and near misses but specialty based critical incidents are very scanty. Aim: In this audit, we aimed to report critical incident and near misses during conduct of obstetric anesthesia over a period of two years. Methodology: Critical incident forms were collected, entered, analyzed and categorized on the basis of American Standards Association (ASA), phase of incidents, system involved, and type of errors, outcome and action taken. Human error was further categorized on the basis of their contributing factor marked in form. Results: During the reporting period, 5511 anaesthetics were administered and 55 reports were received out of which 53 reports were included in analysis. Fifty three reports were divided into 33 critical incidents and 20 near misses. Out of 33 critical incidents, 54.5\% involved CVS system and musculoskeletal system, followed by neuromuscular $(\mathrm{n}=5)$, drug related $(\mathrm{n}=4)$, airway/respiratory system $(\mathrm{n}$ $=2)$, central nervous system $(n=2)$ and renal system $(n=1)$. Forty five incidents possess no untoward effect while 7 led to minor and only one to severe physiological disturbance. Human errors were $(\mathrm{n}=30) 57 \%$ reports and failure to check was the main contributory factor. Conclusion: Critical incidents reporting needs to be introduced in sub-specialties at departmental, national and international level. Checking of equipment, medication and anesthesia machine must be part of regular checks in elective and emergency cases.
\end{abstract}

\section{Keywords}

Obstetric, Anesthesia, Critical Incident, Quality Improvement, Adverse Events, Outcomes

\section{Introduction}

A critical incident is an incident that can be potentially harmful to a patient 
during anesthetic management [1]. A near miss in an event under anesthesia care can possibly lead to negative outcome if not intervened timely [2]. One of the methods of establishing and improving safety in our practice is reporting, sharing and discussing our mistakes, at some forum like Critical Incident reporting. Department of Anaesthesiology at Aga Khan University Hospital, Karachi, Pakistan has a critical incident reporting mechanism in place since 1996 [3].

As health care is moving towards specialty and sub-specialty based practices all over the world. It needs to be incorporated in our set up as well and as a first step, we start critical incident reporting in labor room suite where twenty four hours anesthesia services are available for one elective, one emergency theatre and labor room epidurals. Empty forms are available in both operating rooms of the Labor room operation room (LROR). These are filled on a voluntary basis by the medical and paramedical staff anonymously and are periodically reviewed and presented in academic meetings to educate, to increase awareness and to standardize and formulate guidelines. Specialty based critical incident reporting is of value as it is easier to bring changes or improve the system in relatively small clinical areas with a small group of people like pediatric, obstetric, pain etc. Although literature of critical incident in anesthesiology in general is reported, no report from any obstetric unit was found in literature.

In this audit, our aim was to report critical incidents and near misses specifically during conduct of obstetric anesthesia in LROR of our hospital. The secondary objective was to evaluate the contributing factors of human error.

\section{Methods}

All reported incidents occurred in obstetric unit over a period of two years (July 2015 to June 2017) in labor room operation room of Aga Khan University Hospital. The forms are filled prospectively, voluntarily and anonymously in a predesigned critical incident form by anesthesia resident, medical officer and faculty (Appendix). All data variables on this form were entered in Statistical Package of Social Sciences Version 19.0 (SPSS). All forms were reviewed and all incidents were categorized on the basis of type of errors. The desired variables for this audit were segregated in a separate SPSS file. These were then reviewed and re-analyzed by primary investigator. The forms with incomplete contextual information were dealt separately. The following data was reviewed for all reports: surgical procedure, grade of anesthetist who reported the incident, American Society of Anesthesiologist (ASA) status, type of anesthesia, phase of anesthesia when the incident occurred, system involved, type of error, outcome and action taken. We included incidents where the patients encountered harm and "near misses" where the patients did not suffer harm but could have if left to progress. All consultants and trainees are encouraged to report by presenting the collected incidents at a given interval in our obstetric group meeting. The reports were classified as human, system, equipment or medication errors. Furthermore human errors were categorized on the basis of their contributing factors already 
present in the form. Human error is a social label which implies that the individual should have acted differently and thus is responsible for the consequence of that conduct. System error can be defined as an instruction that is either not recognized by an operating system or is in violation of the procedural rules. Equipment error includes faulty equipment. Medication error is any preventable event that may cause or lead to inappropriate medication use or patient harm while the medication is in the control of the health care professional, patient, or consumer.

The following definitions were employed for the respective events: [4]

- Difficult tracheal intubation $->3$ attempts

- Bradycardia/tachycardia - $>20 \%$ deviation from baseline pulse rate

- Hypotension/hypertension $->30 \%$ deviation from baseline blood pressure

- Desaturation- $-\mathrm{SPO}_{2}<90 \%$

- Difficult cannulation $->3$ attempts

- Hypothermia-temperature $<35^{\circ} \mathrm{C}$

\section{Results}

During the review period 5511 anesthetics were administered and 55 critical incidents were reported. Two incidents happened in ward and labor room therefore excluded from our analysis. Henceforth, 53 reports were included in the analysis. Frequency, percentages and p-values were calculated.

Distribution of incidents reported was 20 and 33 critical incidents and near misses respectively. Forty one patients were ASA I and II. Incidents were reported more in elective patients $(n=40 \mathrm{p}$ value $<0.05)$, during day time $(08: 00$ a.m.-05:00 p.m.) $(n=47)$ and more frequently in patients who received regional anesthesia $(\mathrm{n}=40(75 \%))($ Table 1$)$.

Twenty six out of 53 (49\%) incidents occurred at induction of anesthesia and the rest during the pre-induction, maintenance, emergence and post anesthesia care unit.

For ease of understanding, the reports were first divided into critical incidents and near misses $(33+20)$. Out of 33 critical incidents majority of the reported incidents involved the cardiovascular and musculoskeletal system $(9+9=18$ $(54.5 \%))$. Followed by neuromuscular system $(\mathrm{n}=5)$, drug related incidents $(\mathrm{n}=$ $4)$, airway and respiratory system $(n=2)$, central nervous system $(n=2)$ and renal system $(\mathrm{n}=1)$.

The cardiovascular system $(\mathrm{n}=9)$ is one the most common system involved and the most frequent event was hypotension requiring treatment. Another system involved was musculoskeletal system and most common reports $(n=4)$ were during positioning no belt was applied in patients who received regional anesthesia (Table 2).

Twenty incidents were categorized as near misses which were further reviewed and sequenced as equipment, narcotics, infection control, medication and miscellaneous. 
Table 1. Demographics.

\begin{tabular}{|c|c|c|}
\hline Variables & Frequency (n) & Percentage (\%) \\
\hline \multicolumn{3}{|l|}{ Age } \\
\hline $20-30$ yrs & 32 & 60 \\
\hline $30-40$ yrs & 19 & 36 \\
\hline$>45 \mathrm{yrs}$ & 2 & 4 \\
\hline \multicolumn{3}{|l|}{ ASA classification } \\
\hline ASA I & 1 & 2 \\
\hline ASA II & 45 & 85 \\
\hline ASA III & 3 & 6 \\
\hline ASA IV & 0 & 0 \\
\hline \multicolumn{3}{|l|}{ Surgical type } \\
\hline Elective & 39 & 74 \\
\hline Emergency & 14 & 26 \\
\hline \multicolumn{3}{|l|}{ Time of day of surgery } \\
\hline $8 \mathrm{am}-5 \mathrm{pm}$ & 47 & 89 \\
\hline $5 \mathrm{pm}-8 \mathrm{am}$ & 6 & 11 \\
\hline \multicolumn{3}{|l|}{ Grade of Anaesthetist } \\
\hline Supervision by consultant & 47 & 89 \\
\hline Not supervised by consultant & 6 & 11 \\
\hline \multicolumn{3}{|l|}{ Anesthesia technique } \\
\hline Regional Anesthesia & 40 & 75 \\
\hline General Anesthesia & 13 & 25 \\
\hline Total & 53 & 100 \\
\hline
\end{tabular}

Five equipment related reports shown in Table 3 were pressure bag applied on a used drip with 250 milliliters of air, oxygen analyzer not working, suction not working because it was broken from its seal, suction disconnected from its base which was hidden at the back of anesthesia machine and malfunction of OR table in a patient who just received spinal and when we tried to make her lie, supine table started moving in Trendelenburg position. Narcotic and infection control related incidents contributed equally as shown in Table 2. Miscellaneous reports described were elective cases taken without consent, patient taken with wrong pre-op assessment form, surgical staff left the patient at emergence, patient left in Post-Anesthesia Care Unit (P.A.C.U) alone, no response on patients complain and power cable kept on patients arm.

Drug errors were separately looked at and it was found that medication is the main cause in $15 \%$ reports whether it is a human error or system error.

The incidents were also classified according to the type of error. Human error accounted for $57 \%$ followed by system error $19 \%$, patient factors $13 \%$ and 
Table 2. Analysis of critical incident categories $(n=33)$.

\begin{tabular}{|c|c|c|}
\hline Categories & Number & Percentage (\%) \\
\hline Cardiovascular & 9 & 28 \\
\hline Hypotension & 5 & \\
\hline Bradycardia & 3 & \\
\hline No base line B.P & 1 & \\
\hline CNS & 4 & 12 \\
\hline High spinal & 2 & \\
\hline Ineffective spinal & 1 & \\
\hline Tramadol infusion started without physician order in $\mathrm{k} / \mathrm{c}$ of fits & 1 & \\
\hline Neuromuscular & 4 & 12 \\
\hline Succinylcholine lost from loose connector & 1 & \\
\hline Under-dosage of succinylcholine & 1 & \\
\hline No muscle relaxation after succinylcholine & 2 & \\
\hline Medication related & 3 & 9 \\
\hline Syntocinon given after delivery of first baby in twin pregnancy & 1 & \\
\hline Overdosage of syntocinon in STAT & 1 & \\
\hline Transamine 1 gm given in few seconds & 1 & \\
\hline Airway/Respiratory & 2 & 6 \\
\hline Vomiting under spinal because of wrong h/o NPO & 1 & \\
\hline Unanticipated difficult airway & 1 & \\
\hline Renal & 1 & 3 \\
\hline No urine in bag...faulty urine bag connector & 1 & \\
\hline Others & 10 & 30 \\
\hline Belt not applied & 4 & \\
\hline Lower limb dropped from table under spinal & 2 & \\
\hline OR table/trolley not locked during shifting & 2 & \\
\hline Patient moved without co-ordination & 1 & \\
\hline Discrepancy in blood group & 1 & \\
\hline Total & 33 & 100 \\
\hline
\end{tabular}

equipment failure $11 \%$. Analysis of the causes of those 30 human errors revealed failure to check (equipment/drugs/doses) which was top on list resulted in 12 incidents, followed by lack of judgment $(n=8)$, haste $(n=5)$, heavy work load ( $\mathrm{n}$ $=3)$ and lack of knowledge/experience $(\mathrm{n}=1)$ and lack of assistance $(\mathrm{n}=1)$.

Patient outcome was categorized as: no effect in 45 (85\%) cases, minor physiologic disturbance in 7 (13\%), severe physiological disturbance in $1(2 \%)$ and zero morbidity and mortality.

\section{Discussion}

An audit is a systematic process whereby medical practice is assessed and improved [5]. Though literature is available on critical incident reporting in 
Table 3. Analysis of near misses $(n=20)$.

\begin{tabular}{|c|c|c|}
\hline Incident categories & Frequency & Percentage \\
\hline Equipment related & 5 & 25 \\
\hline Pressure bag applied on a used drip with $250 \mathrm{mls}$ air & 1 & \\
\hline No suction pressure as suction bottle cap broken & 1 & \\
\hline Suction tube disconnected & 1 & \\
\hline Malfunction of operation table just after spinal & 1 & \\
\hline Oxygen analyzer was not working & 1 & \\
\hline Narcotic & 3 & 15 \\
\hline Unlabeled narcotic & 1 & \\
\hline Expired Injection Pethidine in stock & 1 & \\
\hline Inj. Morphine given by pharmacy instead of Inj. Fentanyl & 1 & \\
\hline Infection control & 3 & 15 \\
\hline Fungus in spinal pack & 1 & \\
\hline Sterile glove torn by sharp nails not noticed by primary person & 1 & \\
\hline No proper mask cap inside OR & 1 & \\
\hline Ampoule & 2 & 10 \\
\hline poor quality ampoule lead to glass cut & 1 & \\
\hline Vasopressor not available in OR & 1 & \\
\hline Miscellaneous & 7 & 35 \\
\hline Nurse left patient during spinal anaesthesia & 2 & \\
\hline Pre-operative evaluation and patient swap & 1 & \\
\hline Power cable kept on arm rest of OR table & 1 & \\
\hline Patient c/o pain in PACU but no one attending her & 1 & \\
\hline All surgical staff left OR and patient without information & 1 & \\
\hline Elective LSCS taken without consent & 1 & \\
\hline Total & 20 & 100 \\
\hline
\end{tabular}

anesthesia [6] [7] [8] but data is lacking in terms of specialty based critical incidents from the South Asian region. One of the objectives of these efforts is the use of critical incident reporting as one of the quality improvement method. It can be used as a tool for increasing awareness among anesthesiologist and trainees, preparation of policy/guidelines and their implementation, step to prevent medication error and identification of faulty equipment. It is of particular value in developing countries because of its low cost of setting and running the program. We have been using this tool in our department since 1996 and have found it useful.

The paradigm shift towards regional anesthesia over the past decades has made obstetric anesthesia safer and reduced mortality. Data relating to critical incident (CI) in obstetric anesthesia is deficient. Our result shows highest per- 
centages of cardiovascular event in comparison to other reports where respiratory problems were commonest. Tay et al. from Singapore reported 297 critical incidents, where $77 \%$ were respiratory events with $35.7 \%$ laryngospasm [9]. Marcus et al. reported airway/respiratory events as $52.2 \%$ of all incidents [10]. We found only $6 \%$ airway/respiratory incidents. The reason behind this disparity is the rate $(75 \%)$ of regional anesthesia which prevents airway/respiratory issues.

The highest incidents were found during the day time (8:00 a.m. - 5:00 p.m.), among elective patients mostly ASA I and ASA II patients. It does not mean that incidents do not occur during odd hour rather odd hour duties are more prone for critical incidents and morbidities. Direct consultant supervision is mostly responsible for appropriate reporting during these hours. Under reporting during on call hours is related to many factors like under supervision, denial of the fact that it is an error and desire to conceal if anything goes wrong. However, many investigators have concluded that voluntary reporting can result in underestimation of frequency of problems, but not necessarily the nature of problems [7]. Different causes of under reporting are present in literature with the reason of lack of ownership [11], lack of interest in sharing the experience and lack of time to fill these forms [12]. Accuracy in filling contextual details is very important to capture the actual fact and to make sense out of it.

Drug errors (15\%) were not very high but still very crucial in the practice of anesthesia and most of these incidents involve dispensing and administration issues. It has been recognized that obstetric patients are at a greater risk as we are dealing with two lives. Approximately $11.3 \%$ of our incidents were equipment related. This was lower compared to Vander Walt et al. who reported 14\% which is nearer to our report but contrary to Tay's report of $4.4 \%$ equipment related incidents [9] [13].

Majority of incidents (59\%) were related to human error which is similar to earlier reports (ref no). Though human errors are not easily correctable errors but contributing factors need to be identified with continuous reinforcement for adherence with guidelines and policies, change of attitudes and alteration of systems to ensure check and balance at different steps. Elhalawani recommends dividing human errors into organization accidents or unsafe act, and further divide unsafe act into intended and unintended action to get more useful information [14]. Human error reporting is the product of direct consultant supervision who observe and educate his/her trainee regarding his performance and motivate them to learn how to report it. Reinforcement and revision of existing protocol and processes as well as specific new protocols or structured courses in crisis management could be introduced. Effectiveness of these strategies in our practices is still required [15].

Regarding outcome, our results demonstrated that majority of incidents resulted in no harm, and $13 \%$ lead to minor physiological disturbance and only 1 report of morbidity. The report of morbidity shows that spinal was instituted while doing co-load with crystalloids and patient became tachycardiac (up to 
170/minute) and unconscious. She required intubation and resuscitated with fluid. The root cause of this incident was hypovolemia secondary to inefficient volume resuscitation at the time of spinal administration. Though there were two cannulas (18 G and $22 \mathrm{G}$ ), large bore cannula was swollen and no one noticed that how much fluid was infused. No mortality reported during this period could be because of vigilance, better monitoring and optimization of patients and quick response on these critical incidents.

Several safety issues were highlighted from our Critical incident reporting System (CIRS) which allowed us to assess errors in more details and recommend change in practice. Following are few actions taken on these incidents to prevent future incidents:

1) Incidents with educational value and increasing awareness: Some of issues highlighted and reinforced to all health provider teams in LROR were application of safety belt, removal of air from drips before applying pressure bags for rapid infusions was demonstrated and taught to trainees and technicians, demonstration of how to operate table and its problem shooting done for all team members, reinforcement of medication labels by clear adhesive tape to prevent the labels falling off and preventing syringe swaps.

2) Incidents where specific actions were taken: Poor quality ampoule of Succinylcholine which often causes injury to users was replaced with better drug and printed FLUSH labels were made available to prevent syringe swaps and writing errors.

Limitation of our study is it's under reporting, less frequent reporting in odd hours and no previous baseline data to compare as it is novel in obstetric section.

CIRS is not the only method of evaluation of our system but it could be considered as a low cost method for partial evaluation of a system. It needs to be reinforced by other methods like feedback system, medication, clinical and equipment audits; and satisfaction surveys. Sharing of incidents in an open discussion of CIs in meeting of concerned group leads to more appropriate and acute actions and prevention of its reoccurrence. Reporting should not be for the sake of reporting rather the aim should be to share knowledge and improve quality of care.

\section{Conclusion}

Critical incidents reporting needs to be introduced and encouraged in all sub-specialties of anesthesia and critical care system at departmental, institutional and national level to improve patients safety, reduce morbidity and mortality and increase awareness and education.

\section{Financial Support and Sponsorship}

None.

\section{Conflict of Interest}

There is no conflict of interest. 


\section{References}

[1] Smith, A.F., Goodwin, D., Mort, M. and Pope, C. (2006) Adverse Events in Anaesthetic Practice: Qualitative Study of Definition, Discussion and Reporting. BJA: British Journal of Anaesthesia, 96, 715-721. https://doi.org/10.1093/bja/ael099

[2] Saito, T., Wong, Z.W., Thinn, K.K., Poon, K.H. and Liu, E. (2015) Review of Critical Incidents in a University Department of Anaesthesia. Anaesthesia \& Intensive Care, 43, No. 2.

[3] Khan, F.A. and Hoda, M.Q. (2001) A Prospective Survey of Intra-Operative Critical Incidents in a Teaching Hospital in a Developing Country. Anaesthesia, 56, 177-182. https://doi.org/10.1046/j.1365-2044.2001.01528-3.x

[4] Gupta, S., Naithani, U., Brajesh, S.K., Pathania, V.S. and Gupta, A. (2009) Critical Incident Reporting in Anaesthesia: A Prospective Internal Audit. Indian Journal of Anaesthesia, 53, 425.

[5] Yentis, S.M., Hirsch, N.P. and Ip, J.K. (2013) Anaesthesia and Intensive Care AZ: An Encyclopaedia of Principles and Practice. Elsevier Health Sciences.

[6] Cooper, J.B., Newbower, R.S. and Kitz, R.J. (1984) An Analysis of Major Errors and Equipment Failures in Anesthesia Management: Considerations for. Anesthesiology, 60, 34-42. https://doi.org/10.1097/00000542-198401000-00008

[7] Staender, S., Davies, J., Helmreich, B., Sexton, B. and Kaufmann, M. (1997) The Anaesthesia Critical Incident Reporting System: An Experience Based Database. International Journal of Medical Informatics, 47, 87-90. https://doi.org/10.1016/S1386-5056(97)00087-7

[8] James, R.H. (2003) 1000 Anaesthetic Incidents: Experience to Date. Anaesthesia, 58, 856-863. https://doi.org/10.1046/j.1365-2044.2003.03334.x

[9] Tay, C.L.M., Tan, G.M. and Ng, S.B.A. (2001) Critical Incidents in Paediatric Anaesthesia: An Audit of 10,000 Anaesthetics in Singapore. Pediatric Anesthesia, 11, 711-718. https://doi.org/10.1046/j.1460-9592.2001.00767.x

[10] Marcus, R. (2006) Human Factors in Pediatric Anesthesia Incidents. Pediatric Anesthesia, 16, 242-250. https://doi.org/10.1111/j.1460-9592.2005.01771.x

[11] Sharma, S., Smith, A.F., Rooksby, J. and Gerry, B. (2006) Involving Users in the Design of a System for Sharing Lessons from Adverse Incidents in Anaesthesia. Anaesthesia, 61, 350-354. https://doi.org/10.1111/j.1365-2044.2006.04542.x

[12] Smith, A.F. and Mahajan, R.P. (2009) National Critical Incident Reporting: Improving Patient Safety. British Journal of Anaesthesia, 103, 623-625.

[13] Van Der Walt, J., Sweeney, D., Runciman, W. and Webb, R. (1993) Paediatric Incidents in Anaesthesia: An Analysis of 2000 Incident Reports: The Australian Incident Monitoring Study. Anaesthesia and Intensive Care, 21, 655-658.

[14] Elhalawani, I., Jenkins, S. and Newman, N. (2013) Perioperative Anesthetic Documentation: Adherence to Current Australian Guidelines. Journal of Anaesthesiology, Clinical Pharmacology, 29, 211. https://doi.org/10.4103/0970-9185.111726

[15] Khan, F.A. (2011) Editorial-Role of Critical Incident Monitoring in Anaesthesia Risk Reduction. Anaesthesia, Pain and Intensive Care, 15, 2220-5799. 


\section{Appendix}

Critical Incident Reporting Form

Patient's age: Surgical Procedure: Surgical Specialty:

\section{Please encircle the relevant}

Grade of anesthetist who detected the incident: $\quad$ C $\quad$ S.I I $\quad$ R M.O

$\begin{array}{llllll}\text { Grade of anesthetist who reported the incident: } & \text { C } & \text { S.I } & \text { I } & \text { R } & \text { M.O }\end{array}$

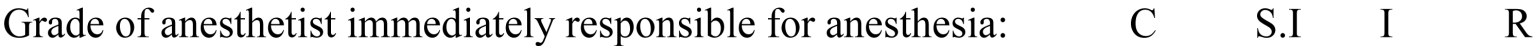
M.O

$\begin{array}{lllllllllllllll}\text { Time of occurrence of incident: } & 1 & 2 & 3 & 4 & 5 & 6 & 7 & 8 & 9 & 10 & 11 & 12 & \text { a.m. }\end{array}$ p.m.

ASA status of patient: $\quad \begin{array}{lllllll}1 & 2 & 3 & 4 & 5 & \mathrm{E}\end{array}$

Type of anaes: G.A. Epidural Spinal G.A. + regional MAC Local block CSE Please tick $(\checkmark)$ the relevant box - Specify event if "Others" box is marked

WHEN DID THE INCIDENT OCCUR: Induction $\square \quad$ Maintenance $\square \quad$ Emergence

\section{SYSTEM INVOLVEMENT}

CVS $\square \quad$ CNS $\square \quad$ Resp $\square$ GIT $\square$ Renal $\square \quad$ N/M $\square$ Others $\square \quad$ Specify
system)

\section{WHAT HAPPENED?}

Airway event

Laryngospasm

Endobronchial intubation

Unexpected difficult airway

Cuff herniation $\square$ Obstruction of ETT $\square \quad$ Failed intubation $\square \quad$ Inability to ventilate Accidental extubation

Problems with LMA

Circuit event Disconnection $\square$

Others $\square$

\section{Equipment event}

Needles $\square \quad$ Syringes $\square$

Monitors $\square$ Intubation aids

table $\square$ Trolley

\section{Others $\square$}

Leak $\square \quad$ Over-pressure $\square$

Cannulae $\square$

N.G. tube $\square$ ETT $\square$

Laryngoscope $\square \quad$ Diathermy $\square \quad$ Gas supply $\square \quad$ Flowmeter $\square$
Vaporize
liaf valve $\square$
Circuit valve $\square$
$\mathrm{CO}_{2}$ absorber $\square$

Tubings $\square$

Connections $\square \quad$ Oxygen bypass $\square \quad$ Scavenging $\square \quad$ Ventilator $\square$

Alarms $\square$

Infusion pump $\square$

Others

Drug event

Underdosage $\square$

Overdosage $\square$

Ampoule/syringe swap $\square$

Wrong

concentration $\square$

Side effect $\square$

Pulmonary event

Hypoxemia $\square$

Allergy $\square$

Interaction

Wrong drug $\square$

Others $\square$

Pulmonary oedema

Hypercapnia $\square$

Pneumothorax
Bronchospasm $\square$

Others $\square$
Aspiration $\square$ 


\section{Cardiac event}

Hypertension needs treatment $\square$

Hypotension needs treatment $\square$ Atrial arrhythmias $\square$

Ventricular arrhythmias $\square$

Bradycardia needs treatment

Tachycardia needs treatment

M. ischemia $\square$

M. infarction

Cardiac failure

Cardiac arrest $\square$

Monitoring event (failure of)
B.P.
E.C.G.
Pulse oximeter $\square$
Nerve stimulator $\square$
Temperature

probe $\square$

Capnography $\square$

Transducers $\square \quad$ Others $\square$

Positioning event

Burn $\square \quad$ Dislocation $\square \quad$ Fracture $\square \quad$ Pt. dropped $\square \quad$ Pressure $\quad$ sore

Other injury $\square$

Miscellaneous event: $\quad$ Hypothermia $\square \quad$ Hyperthermia $\square \quad$ Others

\section{WHY DID THE INCIDENT OCCUR?}

Patient factors

Equipment failure (with no human error involved) $\square$

Personnel/Human factors $\square$

System at fault $\square$ check $\square$

Lack of: Skill $\square \quad$ Knowledge/Experience $\square \quad$ Judgment $\square$ Assistance $\square \quad$ Failure to

Relieving staff: Detected event $\square \quad$ Precipitated event $\square$

Team factors $\square$ : Poor communication between: Anesthesia team $\square$ Anaes \& surgical team $\square$

IN YOUR OPINION WAS THE INCIDENT PREVENTABLE?

Yes $\square$

No $\square$

\section{DETECTION}

Was the incident detected by: $\quad$ Mechanical monitor $\square \quad$ Clinical observation $\square$

- Status of alarms:

On $\square \quad$ Off $\square$

OUTCOME

- Did the incident result in: No effect $\square$ Minor physiological disturbance $\square$

Severe physiological disturbance $\square$ Morbidity $\square \quad$ Mortality $\square \quad$ Temporary $\quad$ sequlae

Permanent sequlae $\square \quad$ Unplanned hospitalization $\square \quad$ Prolonged hospitalization $\square$

\section{DISCRIPTIVE SUMMARY OF THE INCIDENT}

ROOT CAUSE IN YOUR OPINION:

GIVE SUGGESTIONS TO PREVENT FURTHER INCIDENTS

C: lold data $\backslash$ My Documents $\backslash F O R M S \backslash C$ ritical Incident Reporting Form (2).doc 